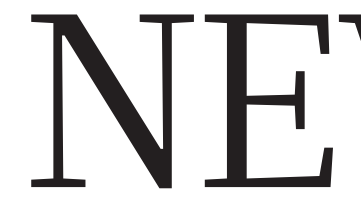

ASTRONOMY $\gamma$-ray bursts shine a light on the early Universe $\mathbf{p . 2 9 0}$
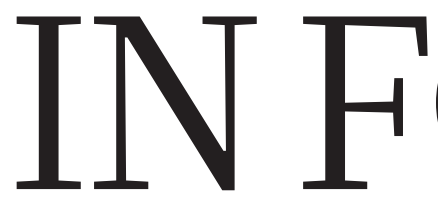

EUROPE Are regulators

MALARIA Gains are threatened by insecticide-resistant mosquitoes $\mathbf{p . 2 9 3}$ too cozy with industry groups? p.294

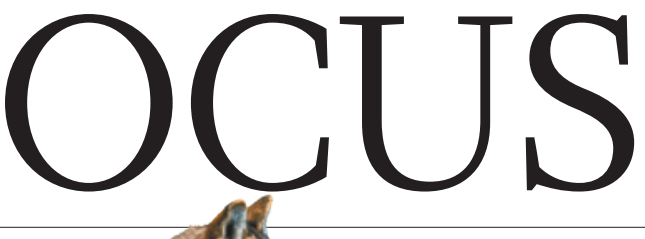

ECOLOGY How the

coyote became North America's top dog $\mathbf{p . 2 9 6}$

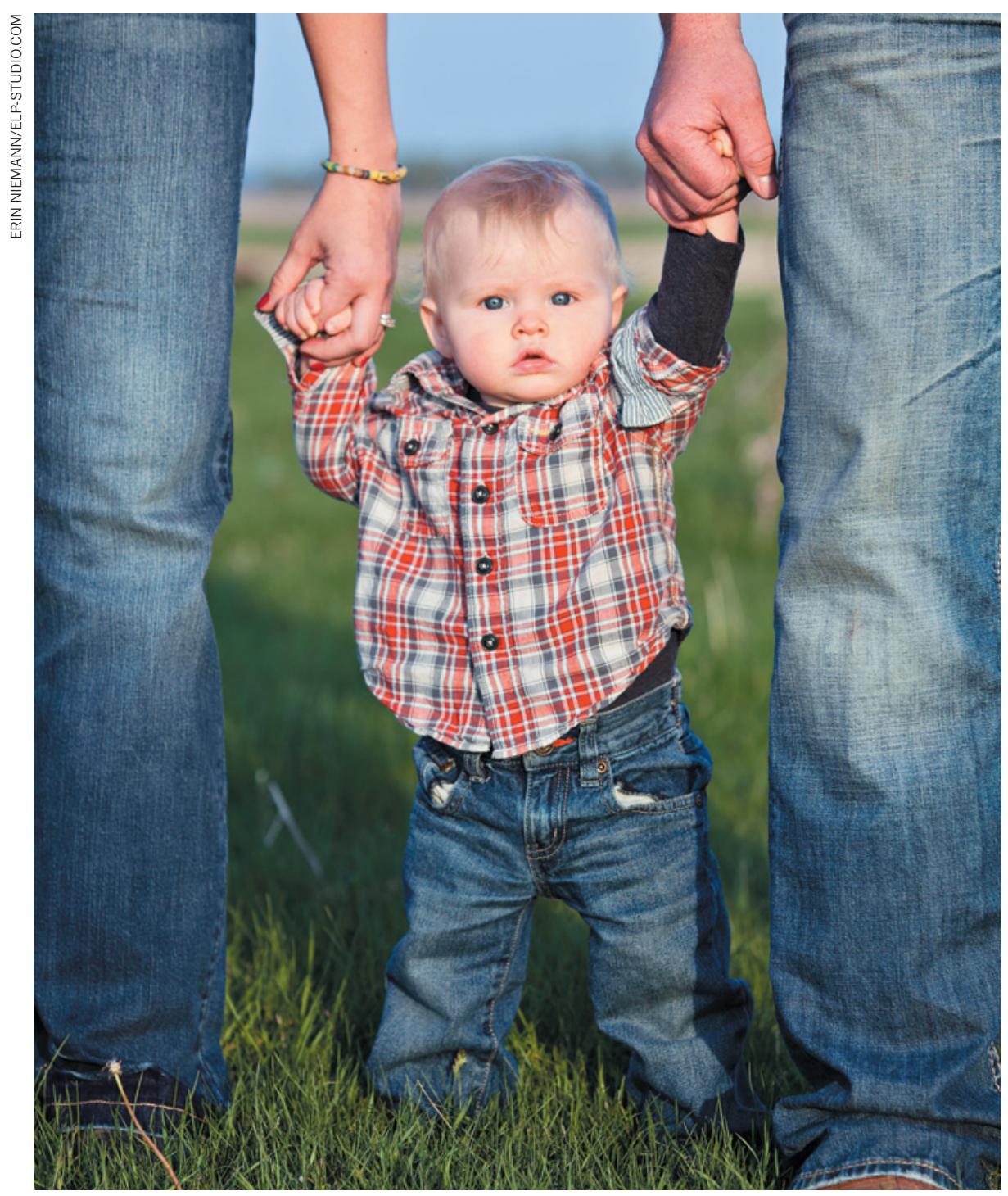

Atlas Thiex of South Dakota is one of almost 3,000 children enrolled in the US National Children's Study.

\section{HEALTH RESEARCH}

\section{Child-study turmoil leaves bitter taste}

Frustration mounts as ambitious US project is scaled back.
Trisha Massmann got a jolt when she received a letter informing her of imminent changes to the US National Children's Study (NCS). She had enthusiastically signed up to the project as an expectant mother in the summer of 2009, after one of its recruiters knocked on the door of her blue clapboard house in the farming community of Granite Falls, Minnesota, population 2,881. By the time Massmann's son, Brett, was born the following February, two fieldworkers from the NCS - a hugely ambitious effort to track environmental and biological influences on the health of 100,000 US children from before birth to age 21 - had spent hours in her home collecting, among other things, dust, air, water and toenail clippings from the parents to be. The same researchers would continue to visit and monitor Brett at regular intervals, becoming a fixture in the family's life.

But in the background, the study has been wracked with budget and management problems and has become a headache for its overseers at the US National Institutes of Health (NIH) in Bethesda, Maryland. In March this year, the disharmony rippled out to Granite Falls, where Massmann's letter informed her that starting in July, the study's activities, including family contacts, would be taken over "for an undetermined period of time" by a researchconsulting firm based in North Carolina.

Massmann immediately sent a text message to Kari Loft, one of the NCS fieldworkers she had grown to know and consider a friend, saying, "I'm not cool with this." Recalling the episode during a visit from Loft this month, Massmann said that before joining the study, she had received assurances that the same fieldworkers would be with her long-term. "That was really important to me. Because they have built up a relationship with my kid." Now, she says, "I don't know if I even want to do it".

Thousands of parents are facing the same uneasy transition as the NCS grapples with its budget woes and undertakes a wholesale restructuring. The affair has unleashed acrimony at all levels, starting with the first seven pilot sites, or Vanguard Study Centers, including the one at South Dakota State University in Brookings, which recruited Massmann. They are slated to shut down this summer, and scores of fieldworkers, including Loft, will lose their jobs. A further 33 pilot sites will face a similar fate when their contracts with the NIH expire over the next 16 months. The NIH 
- says that investigators will be eligible to compete for new contracts, but some are sceptical. "The fact is, we're shutting down. We're done," says Jennifer Culhane, principal investigator for the NCS centre at the Children's Hospital of Pennsylvania in Philadelphia, another of the original seven pilot sites.

Separately, turmoil has rocked the study's advisory committee: two members resigned in March, saying that they weren't consulted about changes in sampling strategy that they feel will undermine the study's scientific value. The affair underscores the organizational challenge inherent in running such a large longitudinal study, but more than that, say critics, it also casts doubt on the NIH's commitment to the study's vision, and to its eventual success.

\section{FROM THE CITIES TO THE SWAMPS}

The NCS was born in 2000, when Congress directed the NIH to study "the effects of both chronic and intermittent exposures on child health and human development". Law-makers specified that the exposures should be biological, chemical, physical and psychosocial, and that the study should address health disparities and monitor US children in all their diversity.

Statisticians at the Centers for Disease Control and Prevention in Atlanta, Georgia, picked 105 sites (see 'A representative sample') for the study, with each meant to recruit about 1,000 pregnancies. The sites run the gamut from urban California to the swamps of Florida: a diverse sample meant to produce findings that could be generalized to all US children, with 40 Vanguard centres launching first and the main study to follow in 2013. There was plenty for Congress to like in a project with such broad representation, which promised to illuminate the roles of environmental factors in diseases such as asthma, autism and diabetes. Repeated attempts by US president George W. Bush to cut the NCS were always thwarted.

However, by 2009, just as fieldworkers were beginning to enrol subjects for the pilot phase, the Senate was accusing the study's thenleaders of a "breach of trust", saying that they had knowingly underestimated its costs by as much as half. The study's director was ousted and replaced with Steven Hirschfeld, a paediatric oncologist and associate director for clinical research at the National Institute of Child Health and Human Development (NICHD) in Bethesda. As of late February this year, the pilot phase had enrolled 2,850 babies; a further 1,200 are expected by the end of the year. By then, the NCS will have spent US\$992 million, or about $\$ 250,000$ per child.

Many principal investigators at Vanguard sites contend that tens of millions of dollars have been wasted on, for instance, an overly complex data-transmission system that requires huge amounts of local programming time.

But with so much invested in local infrastructure, say the study's defenders, jettisoning the Vanguard centres will only multiply the loss.

The move "is so shortsighted", says Rick Holm, a physician who, as chief of staff at the Brookings Health System, helped to build community support for the study. "We made a huge effort to get this started. And the power of community is local."

That sentiment is echoed by Emily Thiex, whose 11-month-old son, Atlas, is a study participant. "It's a National Children's Study," she says. "They should be in every state." Thiex's family works a cattle and sheep farm outside Brookings, so she is well aware that "there are different environmental factors everywhere".

\section{NARROWED FOCUS}

But the NIH has come to see the study as unsustainable. Last month, at a private Senate briefing, Hirschfeld delivered a document stating that the agency will abandon the NCS's goal of representing the United States in a statistically generalizable way. That approach, the document said, could not yield enough subjects "within either a scientifically sound timeframe or a fiscally sound budget". (Speed

\section{A REPRESENTATIVE SAMPLE}

The main US National Children's Study hopes to follow the health of 100,000 children until adulthood, starting in 2013. The 105 original study sites were carefully selected to reflect a range of communities and environmental influences.

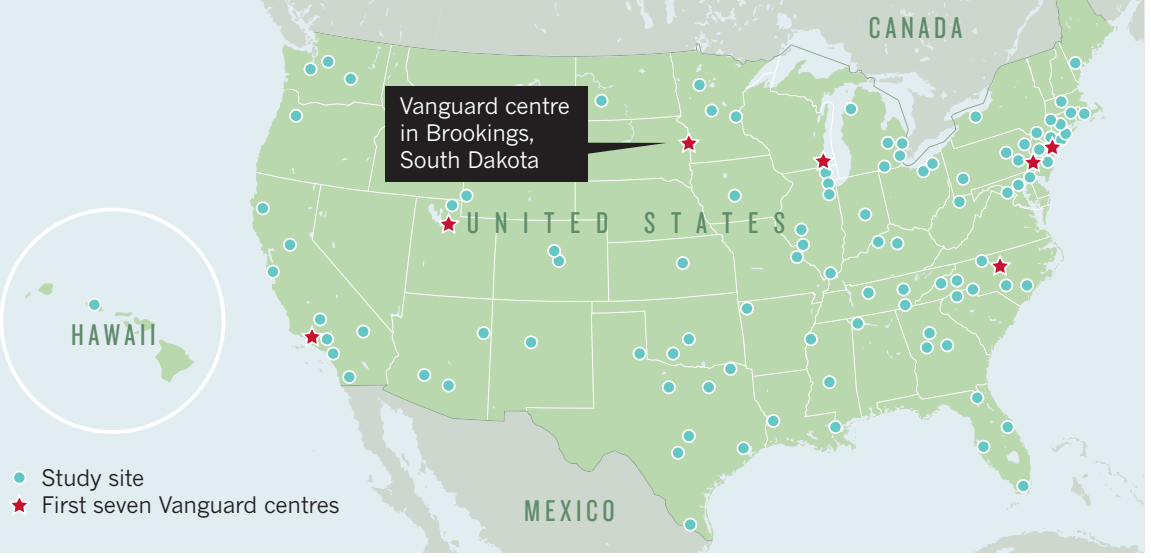

of enrolment is important because environmental exposures change over time.) Instead, the document said, the main study will use health maintenance organizations (HMOs) and "other health care provider networks" as the primary recruiters. When it came to light, critics complained that the strategy would bias the study: only a distinct subset of the US population is covered by HMOs, and there are none in South Dakota, for example.

"It's very sad that rural America is getting the short end of this," says Bonny Specker, the principal investigator at the Brookings centre, which has enrolled more than 400 babies so far - more than any other study site. Others share her concern: at a public meeting of NCS advisers on 24 April, 31 Vanguard principal investigators united to present a white paper arguing adamantly for the scientific need for a generalizable sample.

Hirschfeld will meet government statisticians on 29 May before finalizing the sampling method, in consultation with NIH director Francis Collins and Alan Guttmacher, director of the NICHD. Last week, Guttmacher told Nature: "We are currently exploring whether a hybrid model that is primarily provider-based could be designed so that it still provides a probability sample that would allow generalizability."

The inconsistency of the messages has troubled Congress. Senator Tim Johnson (Democrat, South Dakota) told Nature that he is "disappointed" with the sidelining of the Vanguard centres, including the one in Brookings. He vowed "to ensure the integrity and intent of the study is not compromised".

Senator Thomas Harkin (Democrat, Iowa), chairman of the spending subcommittee that funds the NIH, says: "I am concerned that Congress has appropriated a total of nearly $\$ 1$ billion for this project and we still do not understand exactly how the NIH plans to implement it. We need some clarity."

Others say that the changes to the study are necessary after years of poor leadership and overgrown ambitions. The NIH "allowed the study to take on a form that was completely untenable", says David Savitz, an epidemiologist at Brown University in Providence, Rhode Island, and former head of a Vanguard centre in North Carolina. "For this thing to work there was going to have to be some sort of upheaval."

Hirschfeld defends the changes, made against the backdrop of a proposed $15 \%$ budget cut for the study in 2013. "Unless we make the adjustments needed to ensure that the study can be carried out successfully, we will not be able to realize the vast potential it has to offer," he says.

That is of little comfort to fieldworkers such as Loft, who was going to a job interview after visiting Trisha Massmann this month. In her car after the visit, she burst into tears.

"I feel like I have lied to her," she says. "I haven't. But the study has let her down. I told her I'd follow her and Brett for 21 years. That won't happen." — SEE EDITORIAL P.279 